\title{
TERMINOLOGIAS DE \\ DENOMINAÇÃO DO CHAMADO POVO BUSHMAN: CULTURA ORAL E TRADIÇÃO NA ÁFRICA DO SUL
}

\author{
TERMINOLOGIES OF DENOMINATIONS OF THE PEOPLE \\ CALLED BUSHMAN: ORAL CULTURE AND TRADITION IN \\ SOUTH AFRICA
}

\author{
Elizabete Carolina Tenorio CALDERON ${ }^{1}$
}

Lavinia SILVARES ${ }^{2}$

\begin{abstract}
Resumo: O presente artigo visa apresentar algumas denominações historicamente utilizadas para designar um povo aborígene de uma ampla região sul-africana que atualmente faz parte da África do Sul e de Botsuana. Esse grupo étnico, comumente denominado de Bushman (bosquímano), é caracterizado por uma rica cultura baseada em uma tradição oral de longa data, registrada desde o século XVII por pesquisadores sobretudo de origem europeia. $\mathrm{O}$ estudo apresentado aqui se deu por meio de um levantamento bibliográfico até hoje inédito no Brasil, que inclui artigos, jornais e livros que abordam o tema, além do contato com pesquisadores da região. A presente pesquisa constitui uma etapa de uma investigação mais ampla sobre uma antologia de narrativas que têm sido historicamente atribuídas a esse povo. Tem-se aqui por pressuposto que a escolha de como denominar esse grupo étnico sul-africano está atrelada a visões de mundo distintas, representativas de conflitos históricos marcados por relações de poder e opressão. Uma vez que a autodenominação é pouco utilizada por esse povo específico, propõe-se neste artigo identificar nas formas das famílias linguísticas específicas denominadas como /Xam ou |Xam, por exemplo, uma forma ética e academicamente eficaz para a nomeação.
\end{abstract}

Palavras-chave: Bushman. Bosquímano. San. RAD. Mosarwa. Basarwa. /Xam e |Xam.

\begin{abstract}
This article aims to present some denominations historically used to name an indigenous people from a large South African region that is currently part of South-Africa and Botswana. This ethnic group, which is commonly referred to as "Bushman", is characterized by a rich culture based on a longstanding oral tradition, recorded since the 17th century by researchers who were mostly European. The study presented here took place through a bibliographical survey as yet unpublished in Brazil, which includes articles, newspapers, and books that address the theme, as well as direct contact with researchers from the region. This research constitutes a stage of a broader investigation about an anthology of narratives that have historically been attributed to this people. It is assumed here that the choice of how to name this South African ethnic group is linked to different worldviews, representative of historical conflicts marked by power relations and oppression. Once self-denomination is little used by this specific people, it is proposed in this article to identify in the forms of specific language families named as /Xam or Xam, for instance, an ethically and academically effective form for designation.
\end{abstract}

Keywords: Bushman. San. RAD. Mosarwa. Basarwa. /Xam and |Xam.

1 Escola Técnica Estadual de São Paulo (ETEC), São Paulo, São Paulo, Brasil; elizabete.tenorio@gmail.com;
https://orcid.org/0000-0002-9816-4569

2 Universidade Federal de São Paulo (UNIFESP), São Paulo, São Paulo, Brasil; lavinia.silvares@unifesp.br; https://orcid.org/0000-0002-3781-1574 
- Terminologias de denominação do chamado povo Bushman: cultura oral e tradição na África do Sul

\section{Introdução}

O presente artigo parte de uma pesquisa mais ampla na área de estudos literários em que se pretende compreender a estrutura narrativa de uma antologia de contos oriundos da tradição oral de grupos étnicos nativos da região sul da África, onde atualmente se localizam a África do Sul e Botsuana. O objeto da referida pesquisa é o livro South-African Folk-Tales (1910), do escritor James A. Honey, publicado em 1910 em Nova Iorque, EUA. Em sua introdução, o autor explica que parte das narrativas foram extraídas de publicações inglesas anteriores a 1880, outras são traduções de versões em holandês e algumas são memórias de sua infância passada na região sul-africana. A antologia possui versões distintas de alguns contos identificadas pelo autor em seu índice e no título do conto como "Outra versão da mesma história". A maior parte das narrativas é alegórica e figurativa ${ }^{3}$, tendo como personagens animais como o "trickster" - personagem que usa a esperteza para levar vantagem sobre os demais. As histórias revelam uma série de características morais, reflexões e valores que podem ser interpretados de diversas formas. Há também narrativas que explicam fenômenos da natureza ou da vida humana por meio das ações dos animais. Nesse contexto, o processo de levantamento bibliográfico acerca dos povos conhecidos como Bushman revelou formas muito distintas de denominação ao longo dos séculos, inclusive algumas com teor que hoje se considera ofensivo, pejorativo, inapropriado ou inexato. Pode-se destacar, dentre essas formas de denominação, os termos Bushman, San, Basarwa ou Mosarwa. O presente artigo, assim, constitui uma etapa específica da investigação na qual se pretende discorrer sobre diferentes formas de denominação do grupo étnico ao qual se atribui a origem das narrativas. Tais formas de denominação têm sido empregadas principalmente por instituições governamentais e pesquisadores diversos, como antropólogos e historiadores.

Segundo o antropólogo Alan Barnard (2007) e os historiadores Paulo Fagundes Visentini e Luiz Dario Teixeira Ribeiro (2010), esses povos são habitantes originários do sul da África cuja sobrevivência se baseia na caça, possuindo uma complexa organização cultural e social. Esse grupo étnico faz parte de um coletivo maior denominado Khoisan, que é a raiz comum dessas línguas conforme se estabelece a partir das pesquisas do linguista alemão Wilhelm Heinrich Immanuel Bleek (1875). O grupo Khoisan inclui duas subdivisões: os Khoi, ou Khoe, falantes da língua Khoekhoe, também chamados pejorativamente de Hotentotes; e o segundo grupo, que é o objeto central deste estudo, conhecidos como

3 Os acontecimentos das narrativas estão suspensos em uma relação espaço-tempo não delimitada, o que situa os personagens animalescos em um ambiente imaginário abstrato, apesar de concretamente figurado. Nesse contexto, o caráter alegórico e figurativo refere-se a animais que personificam atitudes que a tradição ocidental talvez classificasse como virtudes e vícios característicos da humanidade. 
San, também chamados de Bushman (BARNARD, 2007). Esse grupo se ramifica em outras línguas denominadas por teóricos diversos como "bushman languages", ou "línguas bosquímanas" (BARNARD, 2007). Seus idiomas comportam dialetos pertencentes a uma mesma família linguística caracterizada pelo complexo som do clique (BLEEK, 1875; BLEEK, 1956) que podem constituir os mais antigos dialetos existentes (KEENEY; KEENEY, 2015). No mapa abaixo, é possível notar a distribuição de alguns destes dialetos:

Figura 1. Distribuição aproximada das principais línguas Khoe e San

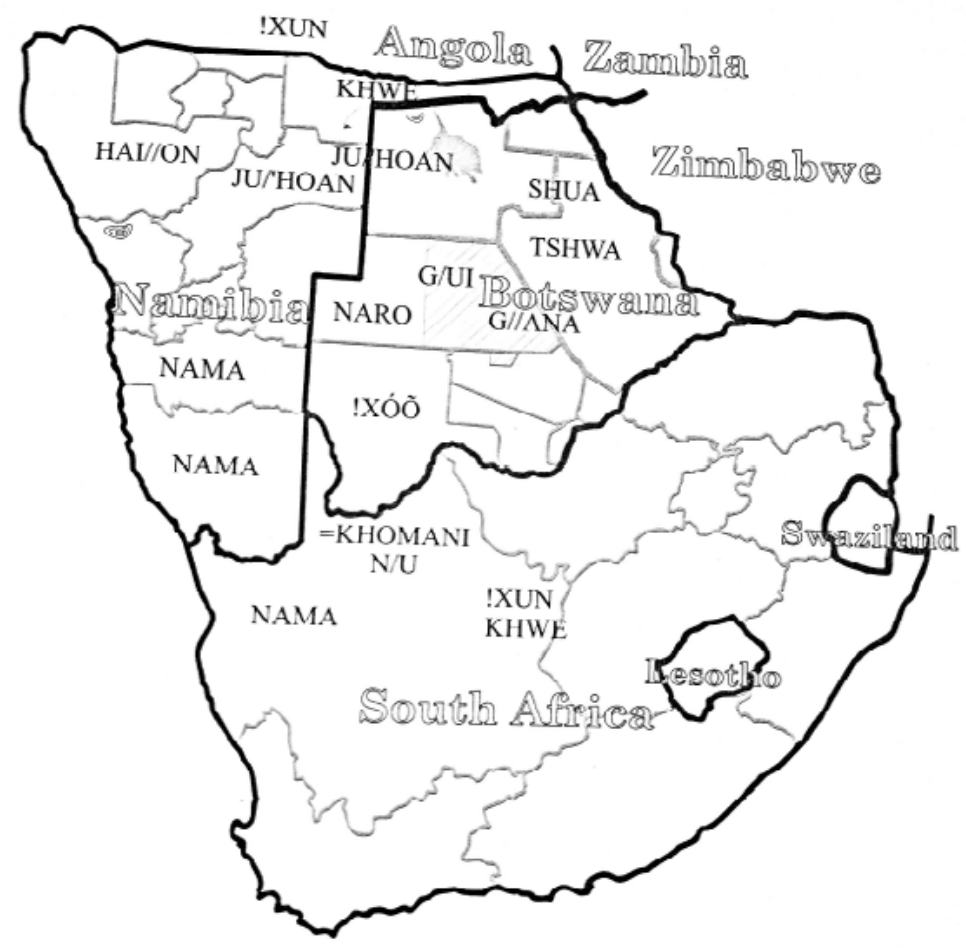

Fonte: Willet, Monageng, Saugestad e Hermans (2002, p. VII)

Atualmente, os povos sobreviventes têm sua cultura negligenciada pelo governo de Botsuana e vivem de forma marginalizada, dependendo do amparo sobretudo de organizações não-governamentais (HALLER, 1994; KIEMA, 2010; TSHIRELETSO; 1997). Mesmo se tratando de uma das mais antigas culturas vivas do planeta (DORNAN, 1925; KEENEY; KEENEY, 2015), no Brasil, os estudos acerca dos Khoisan são parcos. Isso fica evidente na inexistência de trabalhos de pesquisa que contenham os termos de busca utilizados para designar tais povos, como "Bushman", "San", "Basarwa" ou "Mosarwa" no Catálogo de Teses e Dissertações da CAPES. Em contrapartida, a Fundação Alexandre de Gusmão, vinculada ao Ministério das Relações Exteriores, traz uma exceção no documento "África do Sul: História, Estado e Sociedade": o capítulo "O sul da África: das origens à 
- Terminologias de denominação do chamado povo Bushman: cultura oral e tradição na África do Sul

'descolonização branca' (até 1910)", no qual os historiadores Visentini e Ribeiro (2010) discorrem sobre a história da África do Sul antes do apartheid. O texto apresenta uma abordagem histórica dos povos como importantes personagens constituintes da trajetória cultural da África do Sul e informa o cunho pejorativo da designação "bosquímano" (tradução comum para Bushman), fazendo uso do termo San para denominá-los. Contudo, os autores não adentram outras possibilidades de nomeação e não justificam a razão pela qual o termo bosquímano seria ofensivo. Logo, fica perceptível a necessidade de um aprofundamento da compreensão da terminologia utilizada para denominá-los, a fim de amparar nossa própria investigação sobre as narrativas orais atribuídas a esse povo e também proporcionar apoio a trabalhos que venham a desenvolver pesquisas sobre essa temática.

O levantamento bibliográfico realizado para esta investigação é majoritariamente composto de artigos e livros de pesquisadores estrangeiros, uma vez que a produção brasileira sobre o tema é quase nula. Alguns artigos de jornais pertencentes ao século XIX foram utilizados como exemplos de contextualização de algumas terminologias em uso na época. Dentre os autores que são aporte do presente estudo, destacam-se: o missionário etnógrafo britânico Samuel Shaw Dornan, que publica "Pygmies and Bushmen of the Kalahari" (1925), um livro que traz um pouco da visão do século XIX após o contato direto do pesquisador com as sociedades em questão; o antropólogo britânico Alan Barnard, cujas publicações traçam o caminho percorrido desde Dornan até pesquisas mais recentes, como em Anthropology and the Bushman (2007); os professores de teologia africanos da North-West University Johannes J. Knoetze e Rupert Hambira, que fizeram um levantamento que resultou no trabalho intitulado "Basarwa in Botswana: The Role of Perceptions and Name Giving by other Population Groups in Enduring Poverty" (2018); e o artista sul-africano Kuela Kiema, que explica a trajetória de alguns povos de Botsuana em sua biografia "Tears for my Land: A Social History of the Kua of the Central Kalahari Game Reserve" (2010).

O presente estudo não ignora a pertinência da linguística enquanto ciência de evidente importância para esta investigação. Contudo, conforme aponta o levantamento feito pelo antropólogo britânico Alan Barnard (2007), o campo tem se dirigido mais ao estudo das complexas línguas do clique, faladas por estes grupos étnicos, do que à forma de designação das duas ramificações de povos Khoisan propriamente ditas. Ademais, Barnard também explica que os estudos apresentados em Anthropology and the Bushman (2007) abrangem a linguística como importante parte integrante de seu caráter interdisciplinar. Nesse contexto, o teórico explica que, assim como as organizações sociais destes grupos étnicos são sofisticadas, algumas línguas possuem uma complexa sintaxe enquanto outras apresentam maior complexidade em sua fonologia. 
Uma vez que nas sociedades ágrafas, como é o caso do grupo étnico em questão, a palavra detém uma forte ligação com o homem e desempenha papel fundamental na tradição local (BÂ, 2010; FINNEGAN, 2012; ONG, 2012), para os Khoisan, o nome é a forma de diferenciação que determina os elementos do mundo físico (KEENEY, 2015). Logo, a mudança no nome de um elemento da natureza resulta em uma interferência na essência do próprio elemento. Justamente por não terem a escrita como centro de sua expressividade, para estes povos, a palavra está intrinsecamente conectada ao som e ao significado (ONG, 2012). Consequentemente, ela está no cerne da tradição oral, uma prática cultural essencial aos modos de vida destes povos. Nesse sentido, a questão da denominação correta também detém grande valor ético na pesquisa acadêmica sobre esses grupos, uma vez que nessas sociedades a palavra, enquanto forma de designação, possui um valor cultural profundo e distinto do atribuído pela cultura ocidental.

\section{Remote Area Dwellers ou Moradores de Áreas Remotas}

Segundo estudo de Knoetze e Hambira (2018), houve uma tentativa do governo de Botsuana de fazer uso da expressão "Moradores de Áreas Remotas" (ou "Remote Area Dwellers", no texto original) em 1978. A expressão, cuja finalidade era servir a questões geográficas de interesse político após a independência do país, foi abordada para se referir a grupos nativos distintos que residiam em reservas naturais administradas pelo estado. Logo, "Remote Area Dwellers" ou a sigla "RAD" ainda pode ser empregada para designar outros povos em situações precárias de sobrevivência, como reporta o relatório norueguês "Apoio do NORAD 4 ao Programa de Desenvolvimento de Áreas Remotas (PDAR) em Botsuana" ("NORAD's Support of the Remote Area Development Programme (RADP) in Botsuana").

O uso de tal expressão trouxe grande desconforto e não foi adotada por antropólogos e historiadores; as evidentes justificativas para a rejeição são o fato de a expressão caracterizar o grupo étnico por sua situação em relação à posse de terras e pela expressão se referir genericamente a qualquer povo, tribo ou grupo que viva em áreas remotas. No texto "They Are the Government's Children: School and Community Relations in a Remote Area Dweller (Basarwa) Settlement in Kweneng District, Botswana", o pesquisador botsuano Tshireletso (1997) traz depoimentos de professores e outros dados

\footnotetext{
4 NORAD - Norwegian Agency for Development Cooperation, ou Agência Norueguesa de Cooperação para o Desenvolvimento, constitui uma diretoria do Ministério de Relações Internacionais que busca combater desigualdades sociais promovendo assistência a países subdesenvolvidos por meio de cooperação internacional. Para mais informações, ver: https://norad.no/. Acesso em: 27 nov. 2019.
} 
- Terminologias de denominação do chamado povo Bushman: cultura oral e tradição na África do Sul

que denunciam as más condições de sobrevivência nas reservas ${ }^{5}$. Nas palavras do músico e escritor Kuela Kiema (2010, p. 12): “Nós somos chamados de diversos nomes derivados da nossa relação com os recursos dos quais fomos privados" ${ }^{\prime \prime}$. Em outras palavras, essa designação constitui um meio pelo qual o Estado destitui os aborígenes de sua origem e, consequentemente, de seus direitos enquanto seres originários da terra que passou a ser administrada pelo governo.

\section{Basarwa e Mosarwa}

Basarwa, plural de Mosarwa, é um termo utilizado pelos falantes de Tsuana para se referir aos Bushman (HALLER, 1994; KIEMA, 2010), e é usado com maior frequência em Botsuana (WILLET; MONAGENG; SAUGESTAD; HERMANS, 2002) e por acadêmicos (KIEMA, 2010). Tsuana é uma língua do povo bantu, na qual a palavra Basarwa seria usada com o significado de "servo" (KNOETZE, 2018). O antropólogo da Universidade do Arizona Edwin Wilmsen (1990) acrescenta que, de modo geral, o termo pode significar "aborígene" e foi aplicado por falantes de línguas de origem bantu ${ }^{7}$ para referir-se a habitantes nativos da região sul-africana de cerca de dois mil anos atrás. Contudo, o artigo "The Tati Bushmen (Masarwas) and Their Language", de Dornan (1917, p. 41), explica: "Qual é o significado do nome Masarwa? É uma questão interessante e pode ser discutida neste momento. Entre os Basutos, os bosquímanos são chamados de Baroa, pronuncia-se Barwa, nome que pode significar 'homens do sul', de boroa, que significa sul"8. Com o passar do tempo, contudo, o termo Mosarwa passou a representar "membro da desprezível tribo vizinha" ${ }^{9}$ (WILMSEN, 1990, p. 32). Dornan (1917) explica que o termo era considerado uma ofensa: "Eu vi crianças Bechuana que tinham muitas das características físicas dos bosquímanos, mas teriam ficado muito indignadas se eu as chamasse de Masarwas"10 (DORNAN, 1917,

5 É relevante informar que a pesquisa desenvolvida conta com a consulta direta ao pesquisador Lucky Tshireletso, descendente dos Khoisan e cujo auxílio trará maiores subsídios para as próximas etapas investigativas.

6 No original: "We are called various names derived from our relationship with the resources which we have been disposed of".

7 Bantu é o adjetivo usado para designar línguas pertencentes à família lexical banta, predominante em Angola e Moçambique conforme explica a pesquisadora Margarida Petter no artigo "Línguas africanas no Brasil" (2007).

8 No original: "What is the meaning of the name Masarwa? It is an interesting question, and may be discussed at this stage. Amongst the Basutos the Bushmen are called Baroa, pronounced Barwa, a name which may mean "men of the south," from boroa, meaning the south".

9 No original: "member of neighbouring despised tribe".

10 No original: "I have seen Bechuana children who had many of Bushman physical characteristics, yet they would have been most indignant if I had called them Masarwas". 
p. 40). Alan Barnard (1992), Peter Mitchell (2002) - professor de arqueologia africana -, e Wilmsen (1990) afirmam que o termo Basarwa surgiu no século XIX e foi adotado por antropólogos. O arqueólogo e pesquisador John E. Yellen (1985) explica que, assim como a nomeação Bushman, o termo inclui falantes de distintas línguas Khoisan.

Para a historiadora botsuana Lilian Mafela (2009), o termo Basarwa pode ser usado, uma vez que há pesquisas recentes que fazem uso da nomenclatura para abordar os Khoisan de Botsuana. Entretanto, a justificativa de Mafela aparentemente não se sustenta, já que estudos recentes não têm justificado a escolha dos termos Basarwa ou Mosarwa. Apesar de muitos estudiosos usarem o termo, o antropólogo americano Wilmsen (1990) explica que, durante o processo de redistribuição de terras em Botsuana iniciado no século XIX, o termo passou a ser empregado com cunho pejorativo, pois os Tsuana estavam em uma hierarquia social superior aos Khoisan. Em Botsuana, a estrutura colonialista se manteve mesmo após a independência e diferenças étnicas e linguísticas tornaram-se barreiras hierárquicas que segregavam os próprios nativos, o que constituiu uma clara desvantagem para o povo Khoisan.

Tal fenômeno pode ser contextualizado pela vivência do escritor de origem Khoisan Kuela Kiema (2010), que descreve essa denotação negativa em sua biografia. Segundo o autor, o povo Kua, que constitui uma ramificação do povo Khoisan ao qual ele pertence, odiava ser chamado de Basarwa pelos professores nas escolas da Reserva Central do Kalahari. Tal nome era usado pelos Setsuanas para designá-los enquanto servos inferiores. Nas palavras da socióloga Rachelle Winkle-Wagner (2006, p. 94): "o termo "Basarwa" ou "Mosarwa" é frequentemente usado como termo depreciativo para designar uma pessoa pobre, uma pessoa ignorante ou alguém que não é inteligente ${ }^{\prime \prime 11}$.

\section{Bushman}

Bushman é um dos termos mais frequentemente utilizados na produção teórica para designar os Khoisan. Atualmente, há pesquisadores que creem que seu uso é ofensivo, enquanto há aqueles que acreditam que seu uso pode ser enobrecido, conforme será exemplificado a seguir.

No livro Pygmies and Bushman of the Kalahari, publicado em 1925, o antropólogo britânico Dornan explica que uma das primeiras vezes em que o termo apareceu foi em um documento datado de 1685 que registra o uso por um líder Hotentote para designar os

11 No original: "the term "Basarwa" or "Mosarwa" is often used as a derogatory term to denote a person from the sticks, an ignorant person, or someone who is not intelligent" . 
- Terminologias de denominação do chamado povo Bushman: cultura oral e tradição na África do Sul

nativos com os quais estava em guerra. Todavia, em publicações mais recentes de Barnard (1992, 2007) e Knoetze e Hambira (2018), há a informação de que os primeiros registros do termo foram empregados por colonos holandeses na Cidade do Cabo e datam de 1682. Em ambos os casos, o termo foi empregado na década de 80 do século XVII por adversários do grupo étnico, indicando uma conotação negativa em situação de conflito na qual os povos nativos estavam em desvantagem.

Etimologicamente, a versão de Knoetze e Hambira (2018) tem maior sustentação, pois, enquanto nomeação atribuída pelos holandeses, o nome bosjemans, do holandês, gerou Bushman em inglês, e pode ser traduzido literalmente como "homem do mato" em ambas as línguas, constituindo uma referência pejorativa ao modo de vida dos grupos (DORNAN, 1925; CHAPMAN, 1996; MAFELA, 2009). Esse cunho negativo aparece na obra de Dornan (1925, p. 40):

O termo Bosjesnan em holandês, Bushman em inglês, foi o nome dado pelos primeiros colonos holandeses a certos hotentotes selvagens, como eles pensavam indicar seu modo de vida. Eles deveriam ter perdido seu gado na guerra, e assumido o roubo e assassinato como meio de vida ${ }^{12}$.

Nesse contexto, a história dos países colonizados mostra que é comum que colonizadores atribuam nomes aos povos colonizados sem muito investigar a seu respeito (KNOETZE; HAMBIRA, 2018; KIEMA, 2010). Na América, temos o claro exemplo da denominação "índio" equivocadamente aplicada, a princípio, aos nativos devido ao fato de se acreditar que a expedição marítima europeia havia chegado às Índias. Mesmo com a revisão histórica do uso do termo índio, sabe-se que ainda há grande propagação dessa denominação.

No final do século XVIII e início do século XIX, o uso do termo Bushman era muito comum entre historiadores e pesquisadores europeus e americanos, o que pode ser verificado no diário de missão do capitão inglês Frederick Marryat intitulado "Mission: Or, Scenes in Africa - Written for Young People", publicado pela primeira vez em 1849. Há também a coletânea de cartas de Anna Barnard (1901) intitulada "South Africa a Century Ago". Ambas as obras trazem um contexto histórico e descrevem com riqueza de detalhes os povos Bushman e Hotentotes. De forma análoga, diversos periódicos ingleses e africanos fazem uso do termo Bushman durante os séculos XIX e XX para se referir aos

12 No original: "The term Bosjesnan in Dutch, Bushman in English, was the name given by the early Dutch settlers to certain wild Hottentots, as they thought to indicate their manner of life. They were supposed to have lost their cattle in war, and had taken to robbery and murder as a means of livelihood". 
nativos da África do Sul; jornais ingleses e australianos do século XIX também usam o termo para designar os povos aborígenes da Austrália, pois no jornal The Boy's Own Paper, de 1899, Hill James faz uso do termo para designar um amigo de seu irmão, que era nativo da Austrália e vivia em uma área coberta pela mata. O artigo "The Bushman - An Aboriginal Duel" do jornal australiano The Australasian (J.A.F., 891) também se refere a um aborígene com o termo Bushman.

Além de ser um conceito incapaz de especificar as sociedades em questão, segundo Kiema (2010), o termo podia referir localmente pessoas que não possuíam apego emocional à terra e nenhum senso de propriedade; logo, suas terras seriam facilmente tomadas por colonizadores. Essa representação fica visível na fala do antropólogo Dornan (1925) segundo a qual os Bushman são indivíduos sem desejo de posse de bens materiais ou terras. Apesar de Barnard (2010) afirmar que os primeiros pesquisadores a fazer uso do termo no final do século XVIII não o terem empregado de forma pejorativa, todos os significados do nome Bushman atuam como instrumento de justificativa para que povos dominantes continuem a negar o direito que estes grupos nativos têm à própria terra, sujeitando-os a uma vida marginalizada e sem acesso a recursos básicos (BOTSWANA, 1996; PRADA-SAMPER, 2012; HALLER, 1994; KIEMA, 2010). Logo, é possível inferir que os colonizadores atribuíam o nome Bushman a qualquer nativo que vivesse em condições que os europeus, de modo geral, não julgassem "civilizadas". Por este motivo, a nomeação de grupos étnicos baseava-se em critérios amplos e genéricos como o tipo de lugar habitado, sem grande preocupação sobre a cultura dos povos ou mesmo sua especificidade linguística.

Há também a possibilidade de, durante o início do processo de colonização, os primeiros colonizadores terem usado esses termos como uma forma mais rápida e conveniente de identificar alguns povos naturais da terra tomada. A conveniência na designação é evidenciada no artigo "The Bushman Boy", do jornal "The Juvenile Missionary Magazine" assinado pelas iniciais W.W. (1845). O artigo traz a seguinte nota de rodapé para explanar o termo Bushman: "Eles são hotentotes: vivem na África do Sul e são chamados de bosquímanos, por terem vivido uma vida errante entre os arbustos, as montanhas e outros lugares não cultivados ${ }^{13 \prime \prime}$ (W.W., 1845, p. 105). A designação Bushman seria pautada na sua perspectiva cultural acerca do habitat desses povos; contudo, por ausência de interesse nos seus aspectos culturais, o uso do termo generalizado passou a ser difundido, sendo utilizado posteriormente até mesmo por antropólogos de renome, como Dornan $(1925,1917)$.

13 No original: "They are Hottentots: live in South Africa, and are called Bushman, from their having lived a wandering life among the bushes, the mountains, and other uncultivated places". 
- Terminologias de denominação do chamado povo Bushman: cultura oral e tradição na África do Sul

Mesmo com a visível carga semântica negativa agregada ao significado de Bushman, muitas instituições usam o nome devido ao fato de ele estar amplamente difundido, conforme alegam organizações não-governamentais como a Survival International, cujo principal objetivo é divulgar a atual situação desses povos e ajudá-los com recursos básicos como água. Mais recentemente, há teóricos como Bradford e Hillary Keeney (2015, p. XII) que fazem uso do termo na expectativa de que ele seja "gradualmente enobrecido". Não obstante, há correntes de pensamento distintas quanto ao uso da denominação Bushman ter cunho pejorativo. O filólogo polonês Jerzy Koch (2015) traz a seguinte nota de rodapé no livro A History of South African Literature, após mencionar as línguas "KhoiKhoi (Hottentot)" e "San (Bushman)":

O autor está ciente de que, devido aos desenvolvimentos históricos e políticos, alguns nomes próprios, particularmente na África do Sul, são considerados muito ofensivos. No entanto, em um compêndio literário, não se pode evitar o uso de nomes históricos dados a vários povos. Também é preciso ter em mente que esses nomes foram inicialmente usados para fins de classificação e somente com o passar do tempo eles adquiriram seus significados pejorativos. Neste livro, nomes históricos aparecem tanto nas citações quanto no corpo do texto, uma vez que seu objetivo é reconstruir, descrever e interpretar, ao invés de servir a propósitos normativos ${ }^{14}$. $(\mathrm{KOCH}, 2015$, p. 11).

O uso da voz passiva em "alguns nomes próprios [...] são considerados muito ofensivos", associado ao fato de o autor deixar claro que fará uso indiscriminado do termo, evidencia sua opinião favorável em relação à denominação Bushman. Para o pesquisador, o uso inicial dos termos tinha o propósito de classificação, de modo que os termos adquiriram significados pejorativos com o passar do tempo. O fato de Jerzy Koch ter sua obra publicada em 2015 faz um leitor atento interpretar a especificidade de "com o passar do tempo" da frase "[...] somente com o passar do tempo esses nomes adquiriram seus significados pejorativos": conforme exposto anteriormente, o termo provavelmente foi empregado pela primeira vez na década de 80 do século XVII, durante a expansão holandesa no sul da África, contexto em que o povo Khoisan se encontrava em grande desvantagem. Nesse sentido, a afirmação de Koch não está de acordo com os usos iniciais

\footnotetext{
14 No original: "The author is aware that due to the historical and political developments some proper nouns, particularly in South-Africa, are felt to be very offensive. However, in a literary compendium one cannot avoid using the historic names given to various peoples. We also need to bear in mind that these names were initially used for purposes of classification, and only with the passage of time did they acquire their pejorative meanings. In this book historic names appear both in the quotations and in the body of the text, since its goal is to reconstruct, describe, and interpret, rather than to serve normative purposes".
} 
da denominação Bushman explanados por Dornan (1925) e Knoetze e Hambira (2018). Além disso, o próprio emprego do termo "classificação", utilizado por Koch para justificar a existência do termo Bushman remete a um valor negativo. $\mathrm{O}$ ato de classificar remete a uma ideia de catalogação, discriminação e/ou objetificação, pois, quando direcionado a seres humanos, seria preferível o uso de termos como identificar, designar, nomear, entre outros.

A ideia do uso do termo classificação enquanto uma forma de identificação entre diferentes grupos aborígenes não se valida automaticamente como justificativa, pois já se argumentou que o termo era empregado de forma generalizada para identificar povos aborígenes africanos e australianos. Além disso, o termo Bushman já foi utilizado pela mídia australiana para dirigir-se a povos considerados "selvagens", como na publicação The Bushman do jornal The Australasian (J.A.F., 1891). O substantivo descreve com propriedade o tratamento desumano dado aos Khoisan pelos holandeses e, posteriormente, pelos ingleses, que os privaram dos recursos naturais dos quais essas sociedades sempre dependeram para a sobrevivência (VISENTINI; RIBEIRO, 2010). Portanto, a forma de nomeação servia como meio de legitimação da ausência de bens que lhes eram subtraídos (KIEMA, 2010).

\section{San}

Após o uso do termo Bushman, teóricos diversos passaram a empregar o termo San, que pode ser encontrado em publicações atuais para referir-se aos mesmos povos nativos, como no artigo "The forgotten killing fields: 'San' genocide and Louis Anthing's mission to Bushmanland", de José Manuel Prada-Samper (2012). Um outro exemplo de uso da nomenclatura San se dá no artigo "O sul da África: das origens à 'descolonização branca' (até 1910)" (RIBEIRO; VISENTINI, 2010). Em 1996, o jornal The Economist adota o termo para informar o falecimento de uma pesquisadora que conviveu com o povo San por meses com a finalidade de realizar uma pesquisa de cunho antropológico na qual ela vivia a rotina diária dos nativos (OBITUARY, 1996). Contudo, o texto também traz uma explicação entre parênteses: "literally, bush people". O fato de os vocábulos bush e people terem sido escritos separadamente, isto é, na ordem de adjetivo e substantivo respectivamente, pode ser interpretado como uma tentativa de desligamento do termo Bushman, pois a grafia com os termos unidos, Bushpeople, poderia ser empregada como plural de Bushman. Nesse caso, a escolha do autor da notícia direcionou o texto à explicação, pois "literally, bush people" pode ser traduzido como "literalmente, pessoa do mato", o que indica o uso de um adjetivo para atribuir uma característica que auxilie o leitor a relacionar "San" com aqueles que antes eram nomeados Bushpeople. Desse modo, 
- Terminologias de denominação do chamado povo Bushman: cultura oral e tradição na África do Sul

o texto traz a referência Bushman ao mesmo tempo que procura se desvincular dela. A expressão bush people indica o modo de vida rural ou rupestre do povo em questão e traz consigo uma função explicativa ofensiva que, ao evitar o termo Bushman ou bushpeople, remete diretamente à palavra "mato" enquanto suposto habitat dos nativos.

Em contrapartida, a palavra San, oriunda da língua Khoekhoe (RIBEIRO; VISENTINI, 2010; BARNARD, 2007), era utilizada pelos povos que a falavam para designar os parentes mais pobres (BARNARD, 2007). Para os pesquisadores Willet et al. (2002), o nome San é mais comum na Namíbia e na África do Sul. Kiema (2010), bem como Knoetze e Hambira (2018), explicam que o termo San se refere a uma forma particular de subsistência em que os povos vivem de sobras: "a palavra Saa é um verbo Nama-Damara que significa pegar do chão ou de uma lata de lixo por causa da pobreza"15 (KIEMA, 2010, p. 69). Nas palavras de Barnard (2007, p. 5): “O termo 'San' ou 'Saan' (plural de gênero comum) ou o termo 'Sonqua' ou 'Soaqua' (plural masculino) tem sido usado em escritos holandeses e ingleses intermitentes desde o século XVII, seja como uma palavra para Khoekhoe empobrecido ou como um rótulo étnico adequado"16. Apesar da transição de Bushman para San, os informativos jornalísticos do século XIX não deixaram de atribuir adjetivos pejorativos ao povo San, como no jornal The English Gentleman, que no artigo "The Bushman Children, or Pigmy Race (1845)", informa que as crianças San "exibidas para apreciação" do público egípcio, "could not be other than monkeys" ou "não poderiam ser outra coisa senão macacos".

\section{Nomeação por meio de famílias linguísticas: o exemplo de/Xam e $\mid$ Xam}

Conforme exposto anteriormente, os Khoisan são divididos em dois grupos: os Khoi, falantes das línguas Khoekhoe; e os conhecidos como Bushman ou San. Dentre as línguas faladas pelo segundo grupo estão /Xam, ₹Khomani, !Xoõ entre outras. Caracteres como "/","|" ou "!" fazem parte dos idiomas dos povos em questão, que se destacam das demais línguas nativas africanas por possuírem o complexo som do clique, de acordo com o estudo que resultou no livro A Bushman Dictionary, de Dorothea Bleek (1956). A publicação é resultado de um extenso trabalho realizado majoritariamente com registros do linguista Wilhelm Bleek e de Lucy Lloyd, que realizaram um levantamento pioneiro de informações que abrangem da estrutura linguística a narrativas ficcionais dos /Xam (BLEEK, 1956).

15 No original: "the word Saa is a Nama-Damara verb meaning to pick up from the ground or out of a dustbin because of poverty".

16 No original: “The term 'San' or 'Saan' (common gender plural) or the term 'Sonqua' or Soaqua' (masculine plural) has been used in Dutch and English writings off and on since the seventeenth century, either as a word for impoverished Khoekhoe or as an ethnic label proper". 
Na última década, essa nova forma de nomeação com as grafias /Xam e |Xam tem aparecido em publicações acadêmicas para designar os grupos étnicos específicos falantes dos dialetos Khoisan. Isso pode ser exemplificado pelo estudo do antropólogo sul-africano Ansie Hoff, que publica o artigo "Guardians of Nature Among the/Xam San: an Exploratory Study (2011)". Em "'Different people' coming together: representations of alterity in |Xam Bushman (San) narrative", o pesquisador britânico Mark Mcgranaghan (2014) traz o termo Xam. Ambos os artigos trazem os termos próximos às nomenclaturas de cunho pejorativo explicadas anteriormente, mas Mcgranaghan traz o termo em sua introdução como uma forma de situar o leitor acerca do grupo étnico que será abordado e o repete em citações de outras produções teóricas que fazem uso das nomenclaturas Bushman e San. No decorrer do texto, o autor faz uso frequente do termo |Xam (MCGRANAGHAN, 2014). O texto de Hoff (2011), por sua vez, apresenta por diversas vezes o termo San, cujo sentido é complementado pela especificação linguística /Xam. Assim como Hoff, Wessels traz em seu artigo de 2012, "The /Xam Narratives of the Bleek and Lloyd Collection: Questions of Period and Genre", um uso muito mais frequente da designação/Xam do que os termos Bushman ou San.

Segundo Kuela Kiema (2010) e Michael Chapman (1996), os referidos grupos étnicos não fazem uso de uma única nomenclatura para identificar-se. Em sua biografia, Kiema (2010) explica que é um Kua, grupo étnico falante da língua Dxana, que se distingue dos Nharo, por exemplo, que é outro grupo étnico falante de uma língua da mesma família. Nesse sentido, uma vez relacionados à língua dos aborígenes em questão, propõe-se aqui que as nomeações por meio das línguas - como no exemplo de Kua, /Xam e |Xam - se mostram uma forma válida de designação, pois trazem consigo de forma significativa a característica linguística que os povos têm em comum. O uso dos termos /Xam e Kua exemplificam o reconhecimento de um grupo de dialetos, de modo que o mesmo possa ser feito para outros grupos. Nesse sentido, um pesquisador que conhece e se posiciona eticamente diante de seu objeto de estudo pode abordar os Khoisan conforme a família linguística a qual pertencem.

\section{Considerações finais}

As leituras realizadas permitem inferir que o processo de construção das diferentes terminologias de designação dos povos Khoisan tem sido historicamente relacionado a relações de poder que se mostraram desvantajosas para os grupos étnicos em questão.

O termo Bushman (Bosquímano), enquanto primeira nomenclatura utilizada, foi atribuído pelo colonizador holandês munido de uma perspectiva enviesada pelas 
- Terminologias de denominação do chamado povo Bushman: cultura oral e tradição na África do Sul

relações coloniais de poder e preconceito dominantes à época, utilizando-a para designar sem diferenciações aborígenes sul-africanos e australianos. Da mesma forma, Mosarwa e Basarwa indicam uma forma de subordinação dos nativos em relação ao povo Tsuana, outro grupo nativo de Botsuana.

Enquanto Bushman constitui uma denominação colonialista, portanto, Mosarwa e Basarwa contextualizavam a submissão dos nativos a outros grupos, referindo relações hierárquicas entre os povos nativos. A expressão "Remote Area Dwellers" ("Moradores de Áreas Remotas"), por sua vez, busca superar a forma de inferiorização colonial com a justificativa de denominar moradores de uma determinada área, pois a princípio ignoraria as características antropológicas desse povo, ressaltando apenas as características materiais que os levaram a se tornar dependentes do Estado para a aquisição de recursos básicos. Ademais, tanto os termos Bushman, Mosarwa e RAD eram usados para abordar ambas as ramificações dos Khoisan.

Um leitor atento pode se perguntar: não há um termo próprio de autodenominação de tal grupo étnico? Para Willet, Monageng, Saugestad e Hermans (2002), um termo de autodenominação deve surgir apesar de Bushman e Bush People ainda serem muito usados. Atualmente, não há um único termo utilizado pelos povos em questão para se autonomear (CHAPMAN, 1996; KIEMA, 2010). Contudo, alguns autores têm feito uso da base linguística dos povos estudados para especificá-los, como /Xam ou XXm, por exemplo. Os autores que fizeram uso destes termos, de modo geral, ainda empregam as formas Bushman e San com outros propósitos. Mas apesar de toda a conotação negativa relacionada a esses termos, uma pesquisa bibliográfica profícua não poderá ignorar os grandes pesquisadores que fizeram ou fazem seu uso, como Dornan (1925), Bleek (1956) e Keeney e Keeney (2015). Todas as formas de designação apresentadas apareceram em produções acadêmicas diversas e algumas foram populares em jornais do século XIX.

Para longe de constituir um mero preciosismo ou desnecessária especificidade, a opção consciente por uma designação desses povos envolve um aprofundamento da relação do próprio pesquisador com seu tema de investigação, resultando em um conhecimento mais amplo de suas práticas, formas de vida e visão de mundo. Em trabalhos sobre cultura, literatura ou linguagem, esse aprofundamento é experiência necessária para designar um lugar de fala e constituir o objeto do qual se fala. Nesse sentido, o levantamento realizado aponta que as formas linguísticas podem atuar como designações eticamente adequadas, estando o mais próximo possível que se poderia chegar da autodenominação, uma vez que se trata da designação da família linguística dos povos em questão. No caso de uma abordagem menos específica, o termo Khoisan pode ser empregado para um entendimento mais geral, que se refira a povos falantes de línguas distintas. 


\section{Referências}

BÂ, A. H. A tradição viva. In: BÂ, A. H. História geral da África: metodologia e préhistória da África. Brasília: UNESCO, 2010.

BARNARD, A. Anthropology and the Bushman. Nova lorque: Berg, 2007.

BARNARD, A. Hunters and Herders of Southern Africa: A Comparative Ethnography of the Khoisan Peoples. Cambridge: Cambridge University Press, 1992.

BARNARD, A. South Africa a Century Ago. Nova lorque: Dodd, Mead \& CO, 1901.

BLEEK, W. H. J. Bushman Researches. Cape Monthly Magazine, Cape Town, p. 104, 1875.

BLEEK, D. F. A Bushman Dictionary. New Heaven: American Oriental Society, 1956.

BOTSWANA, Ministry of Finance and Development Planning. Study on Poverty and Poverty Alleviation in Botswana by Botswana Institute of Development Policy Analysis. Gaborone: 1996.

CHAPMAN, M. Southern African Literatures. Nova lorque: Longman, 1996.

DORNAN, S. S. Pygmies and Bushmen of the Kalahari. London: Seeley, Service \& Co. Limited, 1925.

DORNAN, S. S. The Tati Bushmen (Masarwas) and Their Language. The Journal of the Royal Anthropological Institute of Great Britain and Ireland, Londres, v. 47, p. 37-112, 1917.

FINNEGAN, R. The 'Oral' Nature of African Unwritten Literature. In: FINNEGAN, R. Oral Literature in Africa. Cambridge: Open Book Publishers, 2012.

HALLER, P. M. When Bushman are Known as Basarwa: Gender, Ethnicity, and Differentiation in Rural Botswana. American Ethnologist, Nova lorque, v. 21, p. 539-563, 1994. 
- | Terminologias de denominação do chamado povo Bushman: cultura oral e tradição na África do Sul

HOFF, A. Guardians of Nature Among the/Хam San: an Exploratory Study. The South African Archaeological Bulletin, v. 166, n. 163, p. 41-50, jun./2011. How to name the 'Bushmen'? Survival International. Disponível em: https://www.survivalinternational. org/material/1156. Acesso em: 28 mar. 2019.

HONEY, J. A. South-African Folk-Tales. Nova lorque: The Baker and Taylor Company, 1910.

J. A. F. The Australasian, Melbourne, 14 fev. de 1891. The Bushman, p. 326.

KEENEY, B.; KEENEY, H. Way of the Bushman as Told by the Tribal Elders. Rochester: Bear \& Company, 2015.

KIEMA, K. Tears for my Land: A Social History of the Kua of the Central Kalahari Game Reserve, Tc'amnquoo. Gaborone: Mmegi Publishing House, 2010.

KOCH, J. A History of South African Literature. Pretoria: Van Schaik Publishers, 2015.

KNOETZE, J.; HAMBIRA, R. Basarwa in Botswana: The Role of Perceptions and Name Giving by other Population Groups in Enduring Poverty. Studia Historia e Ecclesiasticae, v. 44, n. 1, p. 1-16, nov./2018. Disponível em: https://www.upjournals.co.za/index.php/ SHE/article/view/3154/2311. Acesso em: 22 mar. 2019.

MAFELA, L. Changing livelihoods, language use and language shift amongst Basarwa of Botswana. International Journal of Multilingualism, v. 6, n. 3, p. 229-245, ago/2009.

MCGRANAGHAN, M. 'Different people' coming together: representations of alterity in |Xam Bushman (San) narrative. Critical Arts, p. 660-668, ago. 2014.

MITCHELL, P. The Archaeology of Southern Africa. Cidade do Cabo: Cambridge, 2002.

NORUEGA. NORAD's Support of the Remote Area Development Programme (RADP) in Botswana by the The Royal Ministry of Foreign Affairs in 1996. Disponível em https:// bit.ly/39MmDDR. Acesso em: 02 abr. 2019.

OBITUARY - Marjorie Shostak. The Economist, Londres, 19 de outubro de 1996, p. 145. Disponível em: http://tinyurl.galegroup.com/tinyurl/9qSqQ9. Acesso em: 23 abr. 2019. 
ONG, W. J. Orality and Literacy. 3. ed. Nova lorque: Routledge, 2012.

PETTER, M. Línguas africanas no Brasil. África, n. 27-28, p. 63-89, 9 dez. 2007.

PRADA-SAMPER, J. M. The forgotten killing fields: "San" genocide and Louis Anthing's mission to Bushmanland, 1862-1863. Historia, v. 57, n. 1, p. 172-187, maio 2012.

THE BUSHMEN CHILDREN, OR PIGMY RACE. The English Gentleman, London, 16 de agosto de 1845, p. 263.

TSHIRELETSO, L. They Are the Government's Children.' School and Community Relations in a Remote Area Dweller (Basarwa) Settlement in Kweneng District, Botswana. Educational Development, v. 17, n. 2, p. 173-188, 1997.

VISENTINI, P. G. F.; RIBEIRO, L. D. T. O sul da África: das origens à "descolonização branca" (até 1910). In: VISENTINI, P. G. F.; PEREIRA, A. D. (org.). África do Sul: História, Estado e Sociedade. Brasília: FUNAG/CESUL, 2010. p. 17-34.

WAGNER, R. W. An endless desert walk: Perspectives of education from the San in Botswana. International Journal of Educational Development, v. 26, p. 88-97, 2006.

WESSELS, M. The/Xam Narratives of the Bleek and Lloyd Collection: Questions of Period and Genre. Western States Folklore Society, v. 71, n. 1, p. 25-46, inverno/2012.

WILLET, S.; MONAGENG, S.; SAUGESTAD; S.; HERMANS, J. The Khoe And The San - An Annotated Bibliography. Gaborone: Lighbooks, 2002.

WILMSEN, E. The Real Bushman is the Male One: Labour and Power in the Creation of the Basarwa Ethnicity. Botswana Notes \& Records, v. 22, p. 21-35, jan. 1990.

WILSON, M. L. Notes on the Nomenclature of the Khoisan, Annals of the South African Museum. 1986.

W.W. The Juvenile Missionary Magazine, Londres, 1 mai. de 1845. The Bushman Boy, p. 105.

YELLEN, J. The process of Basarwa Assimilation in Botswana. Botswana Notes and Records, v. 17, p. 15-23, jan./1985. 
- Terminologias de denominação do chamado povo Bushman: cultura oral e tradição na África do Sul

COMO CITAR ESTE ARTIGO: CALDERON, Elizabete Carolina Tenorio; SILVARES, Lavinia. Terminologias de denominação do chamado povo Bushman: cultura oral e tradição na África do Sul. Revista do GEL, v. 17, n. 3, p. 46-63, 2020. Disponível em: https://revistadogel.gel.org.br/

DOI: http://dx.doi.org/10.21165/gel.v17i3.2799

Submetido em: 27/12/2019 | Aceito em: 15/09/2020. 